\title{
The Organizational Strategies Of School Management In Japan: Focus On Primary School Principals
}

Makia Cisse, Graduate School of Education, Japan

Toshitaka Okato, Graduate School of Education, Japan

\begin{abstract}
The study examines the organizational strategies of Japanese principals in school management. One hundred principals of primary schools in Hiroshima Prefecture were surveyed in 2007. The samples comprised of the differences between the two groups aged 51-55 and 56-60 in terms of how competency level should be exerted in school. The study was conducted to clarify how principals apply specific organizational tasks in schools. The study used a questionnaire developed to measure the school management skills. The questionnaire composed of a 3 points scale for principal competencies, indicating assessment with the following: low competency, moderate competency and high competency. The principals were considered to be high competent in the area of vision for the organization because of their knowledge of the tasks, the materials to be learned, and their strategies for learning to influence academic success. It recommends that skills must be acquired in order to manage the outcomes of instruction in accomplishment of school objectives. Application of professional responsibilities and leadership in addition to some other tasks can add to the teaching quality. The results provide important information about the relevance of organizational strategies to principals' work, and issues to consider in implementing standard-based school organizational strategies. These strategies have been adopted in school system in the form of formal teacher training (konai kenshu) and effective leadership.
\end{abstract}

Keywords: Managerial skills, Organization strategies, Principals, Effective leadership.

\section{INTRODUCTION}

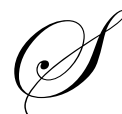

chools are dynamic institutions, which are constantly responding to the needs of children, teachers, parents and so on. After World War II, the provision of quality education for all children became a goal in Japan. The task of management was seen as managing the whole complex human needs comprising of economical, social, psychological, and spiritual factors. Japanese schools modernized the educational process and provide equal educational opportunity to all students (MEXT). According to Shields, Iwama (1989:73), “Japan's school management thrives on teamwork, cooperation, consensus in a group, harmony, group effectiveness, equal treatment of members and devotion to the organization. Japan's school management system as well as Japan's society, are deeply group-oriented systems". He pointed out that "cooperation, participation, and group-centeredness as well, as orderliness, precision and diligence are very important to Japanese school functions as a moral community. Standardized educational system in Japan helps to keep homogeneous, affords learners both equal educational opportunity and socialization into the kind of consensus seeking that characterizes adult life" (ibid, p.76). Okato in JASEA (2008:48) argues that, "the school organization presents an educational vision and the head teacher assists the principal in the task to make action plans of concrete educational activities in order to realize the vision indicated by the principal". In the present study, we examine principal managerial skills in Japan with special focus on primary school. Principals provide job specifications in school where all teachers share educational and other school management activities, thus upgrading their capability to function well. How is school organization structured and what type of leadership is necessary to enhance the functionality of school organizations? It is argued that "positive leaders are those who have high standards of personal commitment and professional competence, give 
support and encouragement to individuals, and take initiatives to establish a sense of cohesion within the school as a whole" (Lloyd, 1985:295). The "innovating head, as it appears, relies partly on exerting influence on staff colleagues as fellow professionals equally. However, he accepts his position as chief executive, and uses the organizational controls, which are available to him in getting things done. The professional and executive considerations reinforce each other as complementary aspect of coherent and unified strategy" (Hughes, 1988:19).

In Japan, "bureaucratic management has spread in pursuit of educational efficiency since the national curriculum was enacted in 1958. Thus, the centralized bureaucratic school system that is seen to promote high standards of test scores forms a dominant structure of Japanese education" (Manabu, in IHB (1992:157). The "informal in-service resources are effective in developing teachers' professional culture in Japan. The richness of these informal in-service opportunities is just the keystone that might guarantee high quality Japanese education" (ibid, p. 165).

Principals and leaders of Japanese schools assume responsibility for the set tasks. They know clearly that each of them is responsible for the given tasks, and they share that responsibility. Moreover, the Japanese decision-making and job responsibility are collective, not individual. They have administrative influence through national, local, and voluntary bodies, and they also exert the responsibilities of student success. Principal strategy to manage is through the implementation and evaluating functional decisions that will enable the organization to achieve its objectives. It is the process of specifying the organization's mission, vision and objectives, as well as developing policies and plans.

\section{OBJECTIVES}

The objectives of this study are to examine the leadership skills and capability of principal organizational strategies in Japanese schools. Also, to evaluate how the organization uses its capacity in responding to the managerial needs. Furthermore, the ability of the principals to plan and work with teachers is vital to effective organization and better coordination of school system.

\section{METHOD}

The samples of the study were made up of one hundred principals of primary schools in Hiroshima Prefecture. The study used a questionnaire method to acquire information from the principals. The questionnaire was design for the respondents on a 1,2,3,4 and 5 scaling units representing very low, low, moderate, high and very high respectively. The samples were made up of differences between the two age groups 51-55 and 56-60 in terms of how competency level should be exerted in school. The different age groups were selected based on the observation that most primary school principals in Japan are within the age brackets of (50-60). All the samples have a minimum teaching qualification of a first degree or postgraduate. Seventy-three of the principals are well experienced, having spent more than twenty years on the job, while the remaining twenty-seven have lesser experience. The questionnaire was composed of a total of 45 questionnaires. shown below:

The questionnaires were composed from a total of 45 questions that falls under three major categories as

(i) What is the organizational strategy employed by school principals in Japan?

(ii) What type of leadership is necessary to enhance the functionality of school organization?

(iii) How does it apply to professional learning and preparation for managerial skills?

Each category is represented in tables 1,2 and 3 respectively. This method is considered reliable to measure the leadership competencies of school principals in Japan. Data collected for the study was analyzed using SPSS 13 package software. The values reported in this study are arithmetic means of respondent opinion on each questions asked. The sample employed compared the general response of the Principals to all the items in the instrument. 


\section{Results}

The results are presented in tables 1,2 and 3 with a graph to explain each (table)

Table 1: School management tasks

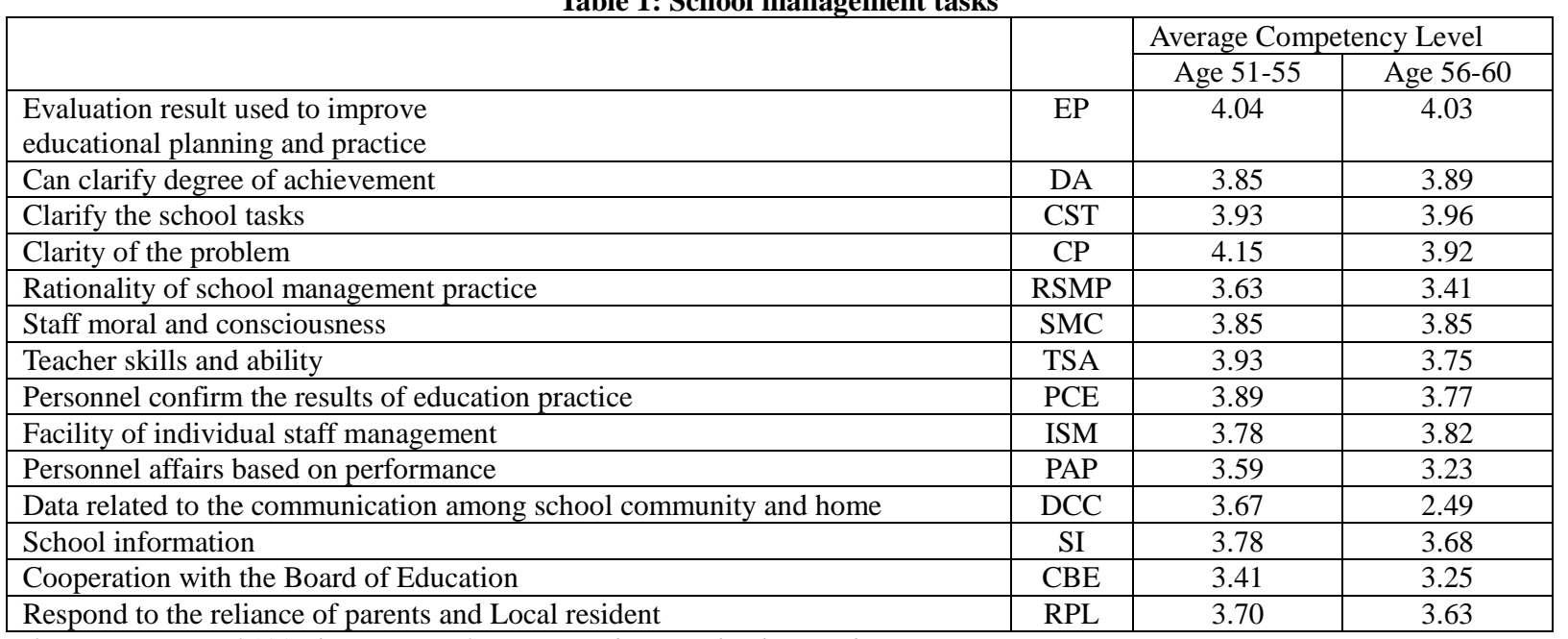

Values are means of 100 observations from respondents in the designed questionnaire.

Figure 1: Graphical representation of management tasks

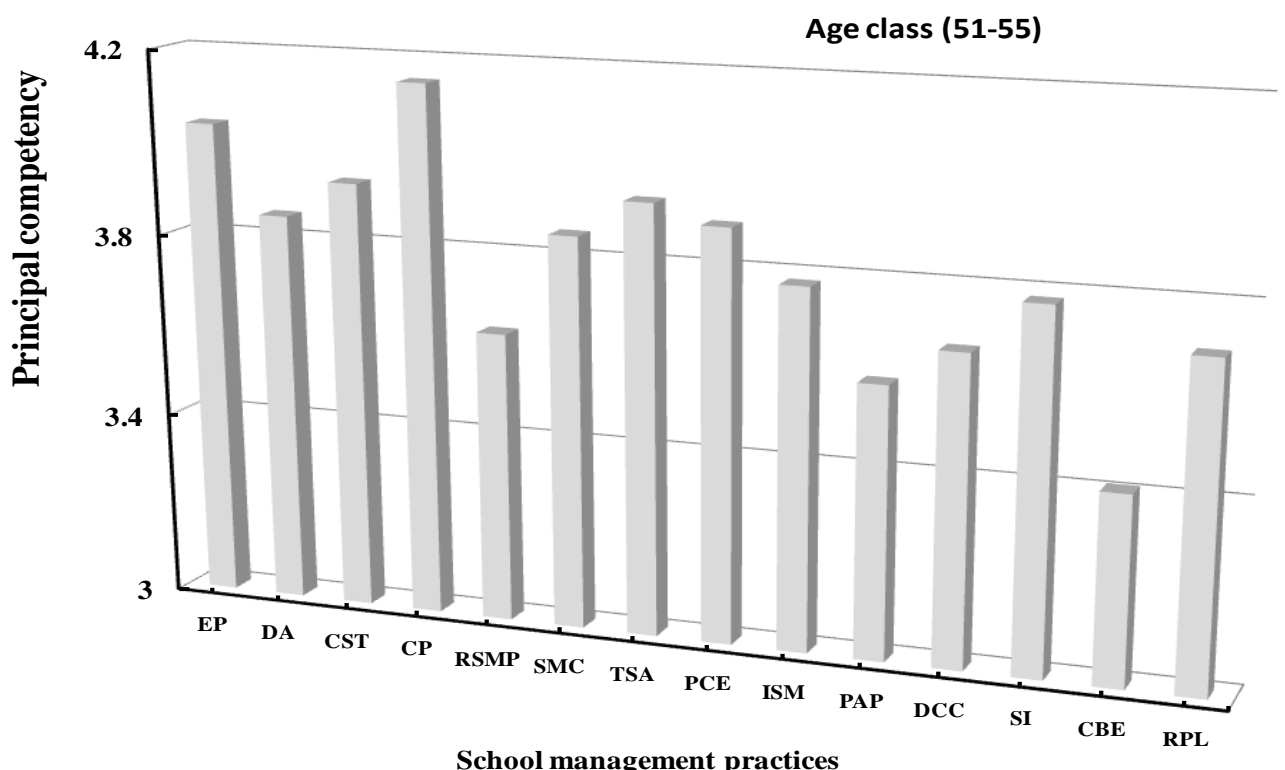




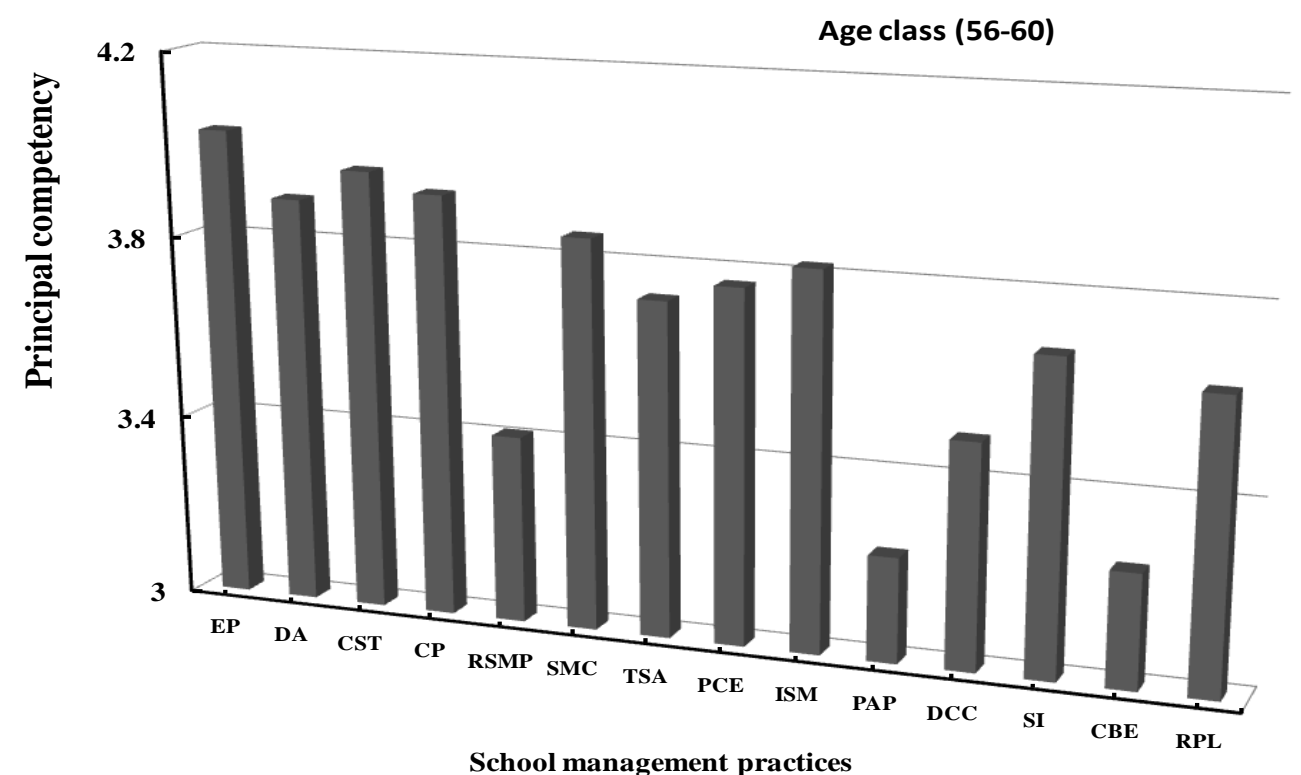

Principals in the age class 51-55, show that the variation between this group. The school management practices with the highest scores values ranges between 3.8 and 4.2, the result show that, their progresses in educational goals are made clear. They also, facilitated methods of instruction so as to interest the abilities of the individual staff and students. On the same hand, they clearly define the problems concerning the school management tasks. While moderate principal competency level scores between 3.4 and 3.8, and our results demonstrated that, principal and their opportunities to learn, skills and ability must be encouraged for good managerial skills. The result shows also that some of the principals help schools to develop plans for improvement such as involving in restructuring programs and in-service activities. Finally, principals groups with low competency ranges from 3 to 3.4 values.

The analysis also shows the age class 56-60 effects on the different management of principals in school management practices. Some of the principals that experience difficulties in their school management task improvement should not take it personally, but consider many other factors, including the nature of relationship with the staffs or the type of the students. However, keeping a high morale is a difficult task.

Table 2: maintaining high standards performance

\begin{tabular}{|c|c|c|c|}
\hline & & \multicolumn{2}{|c|}{ Average Competency Level } \\
\hline & & Age 51-55 & Age 56-60 \\
\hline Long terms education plan & LEP & 3.74 & 3.68 \\
\hline Setting up original educational target & SET & 3.93 & 3.84 \\
\hline Provision of school vision and effective method & VEM & 3.81 & 3.85 \\
\hline Steadfast ideas and values about education & SSE & 3.96 & 3.89 \\
\hline Professional expertise of school function & PE & 3.33 & 3.42 \\
\hline Management capability of school system & MCS & 3.19 & 3.53 \\
\hline Powerful leadership & PL & 3.56 & 3.67 \\
\hline Clear communication and share of school aims & $\mathrm{CS}$ & 3.78 & 3.74 \\
\hline Evaluation quality of educational activity & EQE & 3.80 & 3.49 \\
\hline Educational structure of progress and self-learning & ES & 3.68 & 3.51 \\
\hline Organization arrangement of educational instruction as school leader & $\mathrm{OAE}$ & 3.68 & 3.68 \\
\hline (PDCA) integration between school business process and instruction & SBP & 3.60 & 3.74 \\
\hline Positive development of individual teacher & PDS & 3.84 & 3.77 \\
\hline Consultation & $\mathrm{C}$ & 3.60 & 3.77 \\
\hline Provision of educational idea to all staff & EI & 3.92 & 3.96 \\
\hline
\end{tabular}

Values are means of 100 observations from respondents in the designed questionnaire. 

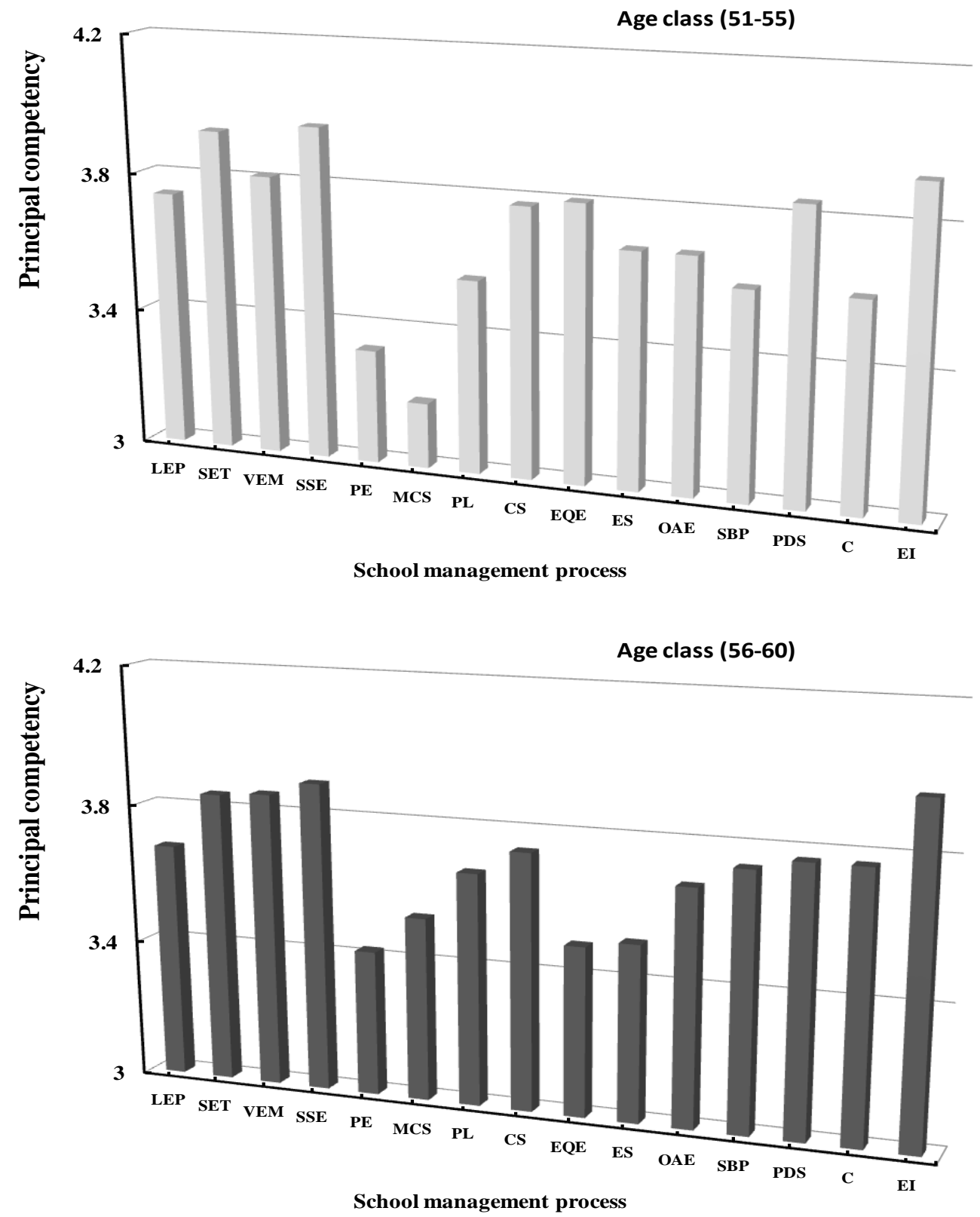

Table 2 above shows the level of competency between principals aged group 51-55 and 56-60. It also shows that those aged 51-55 has a much larger variation in their level of competency with regards to the maintenance of high standards of performance values ranging between 3.8 and 4.2 with high competency level. The high level principal's motivated teachers, created team work in school, and often provided a vision for the whole school, establishing and maintaining a high level staff remains a major developmental task of the school in promoting management issues. Low competency principal scores ranges in values between 3 and 3.4 . It is recommended that this principal group acquire new skills for the management of teachers in schools to understanding teacher professional and staff development; through the creation of opportunities for individual and group learning. In both graphs, analyses of some principals group with moderate competency levels show similar trend in their score values ranging between 3.4 and 3.8. One important finding here is that, the Japanese principals see themselves much more involved in the teachers' professional development. 
Table 3: Establishing a teaching and learning

\begin{tabular}{|c|c|c|c|}
\hline & \multicolumn{2}{|c|}{ Average Competency Level } \\
\hline & & Age 51-55 & Age $56-60$ \\
\hline Teaching observation of the basic and foundation of each subject & TOBS & 3.88 & 3.94 \\
\hline Small group learning & GL & 3.58 & 3.82 \\
\hline Instruction related to class organization according to pupil attainment & ICO & 3.42 & 3.65 \\
\hline Team teachers, two or more teachers teaching a class, except (ALT). & TT & 3.42 & 3.11 \\
\hline Instructional appropriate to the individual program & IAP & 3.80 & 3.89 \\
\hline Instruction which emphasizes expansive learning more than textbook & LT & 2.96 & 3.06 \\
\hline Remedial learning of those who do not adequately reach the content of textbook & RL & 3.76 & 3.69 \\
\hline Absolute evaluation is adopted for academic ability evaluation & AA & 3.80 & 3.88 \\
\hline Instruction that cultivates logical knowledge & ICL & 3.68 & 3.42 \\
\hline Lesson appropriate to the community culture & LPC & 3.76 & 3.32 \\
\hline
\end{tabular}

Values are means of 100 observations from respondents in the designed questionnaire.

Figure 3 shows that, on the average, much competition exists between 56-60 ages group compared to the 51-55 groups. These principals with competency levels between 3.6 to 4 have high rating; they concentrate on conveying teaching observations of the basis and foundation of each subject. They used different techniques for evaluating the performance of teachers. They developed and implemented school improvement and instructional management vision to achieve academic excellency. While in others, principals with moderate competency level score values rating between 3.2 and 3.6. These findings show that this principal group improves discipline in schools and developed strategies for specific plans and quality evaluation. Whereas, low competency group of principals ranges between 2.8 to 3.2. Their roles, move away from instructional to class organization. In all restructuring schools, principals were moving towards the role of facilitator and manager of school cultures.

Figure 3: Graphical representation of teaching and learning

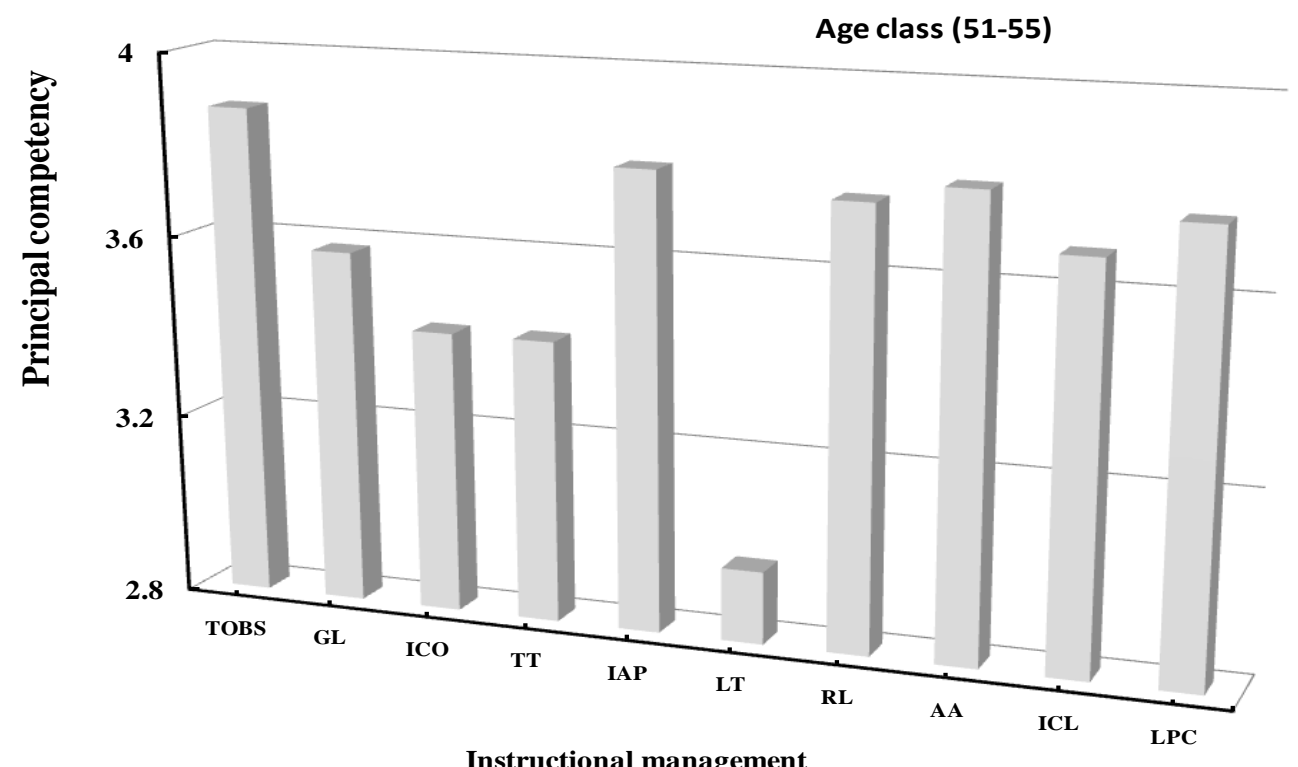




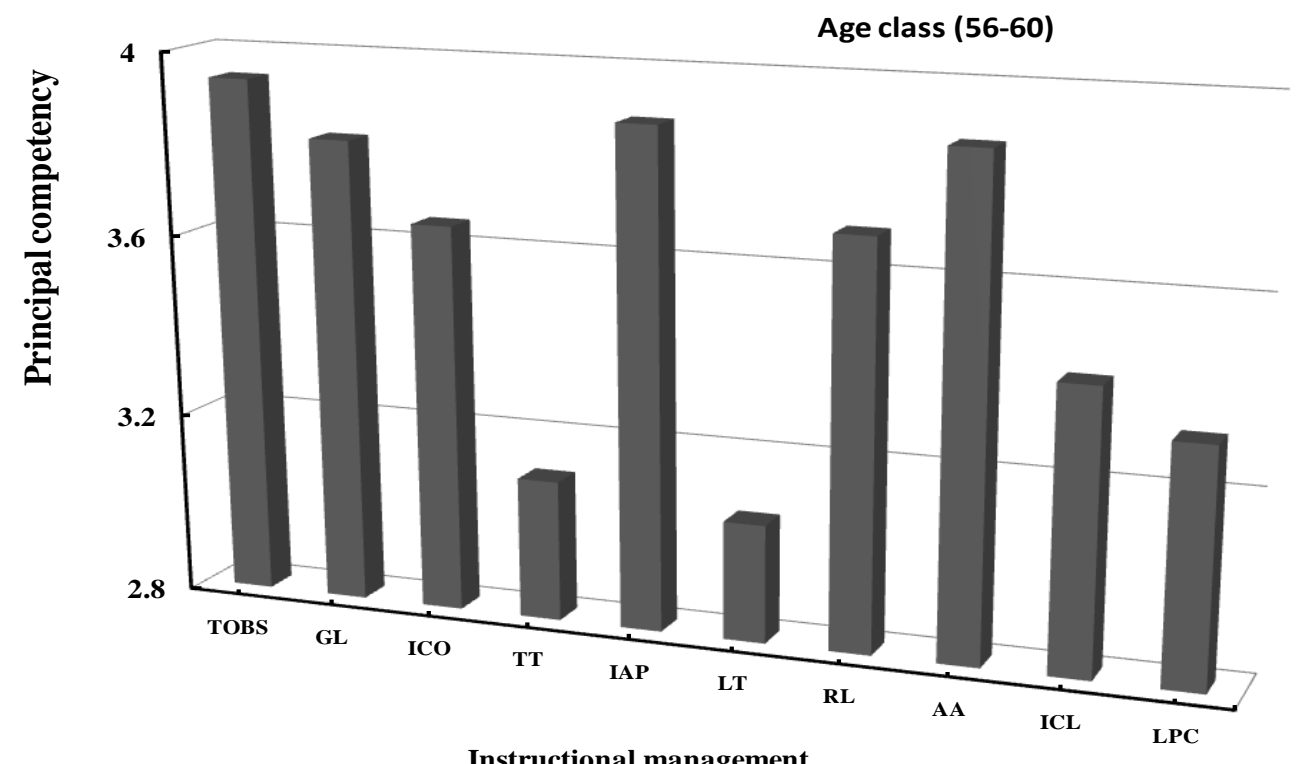

\section{DISCUSSION}

The first group of principals has a low competency, the second group has moderate competency and the third has high competency in the school management practice. Generally, Japanese principals have a minimum qualification of a first degree or postgraduate diploma in education. Each of the principals also has a minimum of more than twenty-years teaching experience. The leadership in Japan is top-down and teachers have pressure to succeed on test scores, active parental involvement and the continued progress of student achievement. The principals need professional competency and organizational skills for school success. For example, one famous Japanese principals, Saito Kihaku, had a vision for school, high expectation for every student. He believes in the importance of basic skills instruction, strong leadership with clear performance goals. It is important to work with teachers and community to develop an efficient school management system. Eraut (1987:737) claims "the notion that a school can function as a centre for cooperative curriculum development and evaluation is central to the problem-solving paradigm, which regards participation in such activities as one of the most productive forms". Kajisa in JASEA (2008:101) argues that, "it is essential for head teachers of curriculum and lead managers to assign head teachers of curriculum duties to develop educational leadership qualities and to effectively apply those qualities in order to become effective curriculum coordinators". Okato, in JASEA (2008:49) says that, "in the school organization, it cannot be said that there is proper implementation of duty if the teachers have to do management work. If there is much management work, it is unreasonable to have only two administrator posts, that is, the principal and head teacher, and, therefore, the number of management staff must be increased". Highly developed countries are currently experiencing surplus of trained teachers; so they have opportunity of selecting among applicants for teaching positions. This kind of procedures could be developed for helping teacher trainees to evaluate their own suitability for the profession and make appropriate decisions.

One group of principals has low competency scores values between 2.8 and 3.2 in the area of instructional management and organizational strategies. Attention should be focused on the analysis of what abilities managers need in order to be effective and to apply appropriate models, principles of organization strategy and improve management, as well as an understanding of education laws and policies. In Oust's study (1993), "teachers with management responsibilities were asked to describe the knowledge, skills and qualities they needed to be able to carry out their main responsibilities effectively". The study sought to identify essential capabilities, which the education manager requires in order to perform effectively in key areas of management. 
Second group of principals has a moderate competency ranging values between 3.4 to 3.8 in the areas of long terms educational planning and practice. Findings by Joseph M., Philip H (1987:196) reveal that, "the people who occupy the principal position are willing to learn new skills and knowledge that clearly relate to the expectations attached to the position". According to them, "principals are to model the learning process for the school, teacher, and students".

Another group of principals has high competency scores ranging values between 3.8 and 4.2. (Table 1, Fig. 1) indicated in the area of clarity of problem and evaluation result used to improve educational planning practice for the school; time management, involvement of staff in school operations, building consensus to solve conflicts, collaboration with families and community, respect for the rights of others and fair treatment of students. Principals are able to communicate this vision to the staff and students, and have the ability to use effective strategies to implement this vision in order to promote positive school success. These findings show that higher academic levels of principals have a positive impact on their quality of teaching and on pupils' learning. But, this does not mean that they have the same management skills. It is also significant to realize the importance of training, impact of the primary principals' work on pupils' learning with mean principal competency of 3.0 of school heads believe that training of teachers is quite good compared with mean principal competency of 1.9 who are mediocre or needs to be improved.

These strategies have been adopted in schools as follows:

Formal teacher training (konai kenshu)

Manabu, Howard (1992:165) argues that, "excellence teachers, who grow in the informal study networks, play very important roles in encouraging teachers' practical study in the school beyond the bureaucratic educational system". This was also shown by Saito. K. (1990), that the support of the local training initiatives is intended to train those teachers especially the new and also some with curricular responsibility, to receive training in their own schools. So, teachers need to improve their teaching and professional development in their own schools. The functions of many opportunities of in-service education should be recognized to form a structure of concentric circle centering on teaching. This finding in this present study shows that this is a peculiarity of Japanese teachers training system.

\section{(b) Effective leadership}

Recent research on school management and organizational strategies in Japan, (Kioka: 2002), found that schools climate, and their social aspect, needs to be change from their present direction to become effective leaders. He recommends that schools must have interest in the high quality teacher evaluation; leadership balance; collaboration, open mind and then, they can improve the teaching quality. As noted by Moore (1970:211) "the manager who has some basis for understanding the problems intrinsic to the professional role and its organizational setting is likely to elicit somewhat greater confidence than would be accorded a mere layman". Gorton (1980:263) argues that, "leadership is an individual or members of a group which contribute significantly to development and maintenance of role structure and goal direction, necessary for effective group performance". In Japan, some school principals' influence was positively related to teacher satisfaction, but the relationship was not statistically significant. Many Japanese school leaders have a close connection with staff development and tasks achievement. Working with support staff in school and relationship between principals, teachers and other members were found to be strong. Generally, there are strong teacher leaders as well.

This study has also shown that the quality of teaching impacts on students' achievement, and thus the relationship between schools and community continue to be strong. They consider education primarily as part of a proper upbringing. An evaluation strategy should serve to assess competence of the principals to assure quality of education. Evaluation processes also functions as tool to improve management skills and knowledge by identifying strengths and weaknesses. This study found that school improvement must be based on local needs. Principals should be supported to create their own plan. That means to assist principals who want to develop a skill about their own in-service efforts as they accept the challenge of improving school organization for students. According to the findings, Japanese principals are actively restructuring school organization to solidify and increase commitment to 
the reform. As also shown by Everad (1984:5), "leadership qualities are indispensable to the effective manager, since principal holds responsibility for motivating the people in his change". On the other hand, Ron (1988:130) argues that, "the complex organizational sub-process, which make up the educational change process are loosely, not linearly coupled". Japanese teachers develop professional relationship with students, and they adopt teaching and learning methods more consistent with lifelong education in their personal and professional lives. Its also involves emotional motivation and attitudinal aspect.

The school management has been interested in the role of the principal and provision of training to increase principals' effectiveness. Pitner (1987:33) argues that, "teachers learn the knowledge and concepts they are taught and can generally demonstrate new skills and strategies if provided opportunities for any combination of modeling, practice, or feedback". It is necessary to have high quality teachers and a coherent process of continuous professional development keeping teachers up to date with the skills required in the knowledge- based society throughout their careers. These findings show that 51-55 and 56-60 groups of principals contribute to improved standard education and they believe the importance attached to policies to increase teacher effectiveness in the schools. In particular, their role to monitor, increase with their responsibility to help teachers to improve their teaching. With this responsibility, principals need to effectively evaluate instruction and assist teachers, as they work to improve their instructional techniques. Parents can make contributions by becoming involved in school activities through participating in extracurricular activities that complement academic work. This is very peculiar to Japanese school system.

\section{CONCLUSION}

The study recommends that the organizational strategies in school should enhance the principal performances relative to all organizational criteria. This argument is one of considerable interest in the context of life-long education. Principals groups; aged 56-60 provide a strong leadership in the community by helping to maintain a shared task, and focus for learning to facilitate the development of the school's mission and academic, social, and civic expectations. The study also shows that the principal is an excellent competent professional with high level of work ethics, who sets a positive example for the school and community as a whole. Kihaku promoted in Japanese schools, a formation of teachers and curriculum including expansion of the quality performance system, improvement of teaching methods and systems such as adopting team-teaching, and implementation of various learning activities. Some principal groups aged 51-55, with moderate competence, must learn new skills and knowledge relating to expectations. And low competent principals have to apply appropriate models and principles of organizational development and management in the understanding of education laws and policies.

This study suggests that principals are expected to have vast experience to undertake a new post. To increase student achievement, it is upon a principal to create a shared vision within the school community and success in implementing organizational structures that engage teachers in sharing decision-making. Schools must demonstrate these strategies by forming and implementing curriculum development vital to the school. It is necessary for the principal and the leadership in general to run the school as a team to promote its effectiveness. The study shows that in Japan, (konai kenshu) training system capabilities developed a significant number of teachers trained. These principals' helps in constantly improving training in the school.

Finally, principals have to prepare school leaders who will understand organizational strategies to demonstrate the application of each of the specific goals. Principals must realize that effective management of their school is important task that can serve as a model for teachers in the school success. Principals' experience will be an asset to manage a school and maintaining high standard for development. Encouraging them to be active in their professional development and their attendance at workshops and conferences would also enhance the work of the school staff. The tasks can be carried out most effectively if the school strategy is founded on ideal philosophy of education and established clear objectives. In this study, the participative strategy in decision-making was found to improve educational activities. School needs to essentially develop reliable means of describing the knowledge and skills that makes up quality education. Moreover, they have to develop the technical and organizational capacity both to measure student achievement against these standards and to determine how school systems are carrying out their responsibilities. The school is now seen as playing more dynamic role and as a catalyst for local community development. 


\section{AUTHOR INFORMATION}

Cisse Makia, I was born in Conakry, Guinea, in July 1972. From 1989 to 1991, I attended Dalaba High School. I enrolled with University of Kankan from 1991-1995. I obtained my Master Degree in School Management and Administration from Hiroshima University, Japan, in 2007. I am presently reading for $\mathrm{PhD}$ in the same University. My main area of study focuses on Principals' managerial skills in Japan. My PhD research is concerned with tasks of managers and their capabilities in Japanese primary schools. I published a journal article on 'Study of school evaluation system in Japan: focus on the perception of principal and vice-principal' in 2008.

\section{REFERENCES}

1. Buckley, J. (1985), the Training of Secondary School Heads in Western Europe, NFER-Nelson, Windson Berks.

2. Dalin, P. (1973) Case Studies of Educational Innovation IV: Strategies for Educational innovation OECD/CERI: Paris.

3. Eraut, M., Pennycuick, D. and Radnor, H. (1987) The Local Evaluation of INSET: A Meta-evaluation of TRIST, Sussex, University of Sussex.

4. Everard, K. B. (1984), Management in Comprehensive School. What Can be learned from Industry? $2^{\text {nd }}$ edition. University of York: Centre for the Study of Comprehensive Schools.

5. Eric Hoyle, Angnes McMahon (1986) The Management of Schools, World Yearbook of Education, published by Nichols publishing company, kogan page New York.

6. Hugh Busher, Rene Saran (1995) Managing Teachers as Professionals in Schools Edited by

7. British Educational management and Ad, society (BEMAS) p151.

8. Howard B. Leavitt (1992) Issues and Problems in Teacher Education an International Handbook, printed in the USA, pp157; 165.

9. JAMES WEIGAND, editor; contributing authors, Roger T. Cunningham ... (1977) Implementing Teacher Competencies: Positive Approaches to Personalizing Education Englewood Cliffs, N.J.: Prentice-Hall.

10. James J. Shields, Jr.(1989) Japanese Schooling, Patterns of Socialization, Equality, and Political Control. Printed in the USA by the Pennsylvania State University Press.

11. Japanese Association for the Study of Educational Administration (2008) Educational Administration and Management in Japan, printed by CENCAGE Learning Asia Pte Ltd.

12. Johnson, J. D. (1993) Organizational communication structure. Norwood.

13. Joseph F. Callahan, Leonard H. Clark (1977) Teaching in the Elementary School: Planning for Competency New York.

14. Joseph Murphy/Philip Hallinger (1987) Approaches to Administrative Training in Education, published bye State University of New York press, USA.

15. Joseph Murphy (1992) The Landscape of Leadership Preparation Reframing the Education of School Administrators Newbury Park, Calif.: Corwin Press.

16. Jerry J. J. Herman (1979) School Administrator's Accountability Manual: tested programs to improve your school's effectiveness, West Nyack, N.Y.: Parker Pub. Co.

17. Jeffrey PFEFFER (1992) Managing With Power: Politics and Influence in organizations Boston, Mass.: Harvard Business School Press.

18. Kioka Kuzuaki (2002) “Educational Critique”, School Management and Organizational Leadership Strategies, printed in Japan p22 26.

19. Larry W. Hughes, Gerald C. UBBEN (1980) The Secondary Principal's Handbook, a Guide to Executive Action, printed in the USA.

20. Macmillan, Hugh Busher \& Rene Saran (1995) Managing Teachers as Professionals in Schools London; Philadelphia: Kogan Page in association with the British Educational Management and Administration Society(BEMAS).

21. Marianne Coleman and Ann R J Briggs (2002) Research Methods in Educational Leadership and Management London: Paul Chapman Publishing.

22. Meredydd Hughes, Peter Ribbins, Hywel Thomas (1985), Managing Education: The Ssystem and the Institution printed by Holt, Rinehart and Winston Ltd UK, p295. 
23. Moore, W.E. (1970), The Professions: Roles and Rules, New York, Russell Sage Foundation.

24. Ministry of Education, Culture, Sports, Science and Technology (MEXT), http://www.mext.go.jp/english/.

25. Nangy, J. Pitner, Dennis Hocevar (1987) An Empirical Comparison of Two-factor Versus Multifactor, Theories of Principal Leadership: Implications for the Evaluation of School Principals, printed by Springer Netherlands.

26. OECD (2002) Knowledge Management in the Learning Society, Education and skill, Paris OEDCA.

27. Ronald W. REBORE (1987) Personnel Administration In Education: a Management Approach, Englewood Cliffs, N.J.: Prentice-Hall.

28. Richard A. Gorton (1980) School Administration and Supervision: Importance Issues, Concepts, and Case Studies, printed by Brown Company in the USA

29. Richard Pascale and Anthony Athos (1981) The Art of Japanese Management. 
NOTES 